\title{
Near-Surface Attenuation and Velocity Structures in Taiwan from Wellhead and Borehole Recordings Comparisons
}

\author{
Yu-Ju Wang ${ }^{1,2, *}$, Kuo-Fong Ma ${ }^{1}$, Shao-Kai Wu ${ }^{1}$, Hsuan-Jui Hsu ${ }^{3}$, and Wen-Chi Hsiao ${ }^{3}$ \\ ${ }^{1}$ Department of Earth Sciences, National Central University, Taoyuan City, Taiwan, R.O.C. \\ ${ }^{2}$ Institute of Nuclear Energy Research, Atomic Energy Council, Taoyuan City, Taiwan, R.O.C. \\ ${ }^{3}$ Central Weather Bureau, Taipei, Taiwan, R.O.C.
}

Received 5 August 2015, revised 18 September 2015, accepted 7 October 2015

\begin{abstract}
By analyzing the data from 28 seismic borehole stations deployed by the Central Weather Bureau Seismic Network throughout Taiwan from 2007 to 2014, we estimated the near-surface velocity (Vp and Vs) and attenuation (Qp and Qs) structures from surface to depths of approximately $300 \mathrm{~m}$. To ensure that the deeper recordings were on the ray path between the seismic source and upper receiver, only events with an incidence angle of less than $35^{\circ}$ were selected. Local magnitudes of analyzed events were between 1.1 and 6.6. The subsurface Qp and Qs were well modeled in the $5-40 \mathrm{~Hz}$ frequency band using the spectral ratio of direct $\mathrm{P}$ - and S-waves, respectively, at each station, under frequency-independent $\mathrm{Q}$ and $\omega^{2}$ source model assumptions. The estimated Vp in the Coastal Plain, the Western Foothills, the Longitudinal Valley, and the Yilan Plain were approximately 1000 - $2000 \mathrm{~m} \mathrm{~s}^{-1}$, which was lower than the Vp of 2500 - $4000 \mathrm{~m} \mathrm{~s}^{-1}$ in the Central Mountain Range. In addition, the Vs in the plain areas were lower than that in the Central Mountain Range. The low Vp and Vs and high Vp/Vs ratio in the Coastal Plain and the Western Foothills can be attributed to the unconsolidated soil and high pore-fluid content of subsurface sediments in the plain areas. In contrast to the velocity distribution, low Qp and Qs were observed in the Central Mountain Range. The low Qp and Qs with low Vp/Vs and low Qs/Qp ratios in the Central Mountain Range was consistent with the high thermal temperature observed in the field investigation. The obtained velocity and attenuation structures near surface could also provide important constraints in validation of the crustal structure of Taiwan.
\end{abstract}

Key words: Borehole, Thermal, Attenuation, Velocity, Taiwan

Citation: Wang, Y.J., K. F. Ma, S. K. Wu, H. J. Hsu, and W. C. Hsiao, 2016: Near-surface attenuation and velocity structures in Taiwan from wellhead and borehole recordings comparisons. Terr. Atmos. Ocean. Sci., 27, 169-180, doi: 10.3319/TAO.2015.10.07.01(T)

\section{INTRODUCTION}

Seismograms, which provide information on earthquake sources and paths, are critically influenced by near-surface unconsolidated sedimentary layers or weathering materials. The anomaly observed in seismic waves, including attenuation, amplification, and scattering, is commonly referred to as a site effect (Abercrombie 1997). In waveform simulation and ground-motion prediction, the site effect is linked to waveform amplification and prolongation of the shaking duration. Thus, understanding the underlying site conditions is critical for assessing seismic risk, improving building codes, and retrofitting existing buildings. In addition, site effects must be correctly calibrated for analyzing earthquake

\footnotetext{
* Corresponding author

E-mail:wangzu885@gmail.com
}

sources and determining rupture dimensions, stress drops, and other source parameters; otherwise, the parameters calculated will be erroneous (Abercrombie and Leary 1993; Abercrombie 1995; Zeng and Anderson 1996).

Two critical factors typically used to characterize the site effect are velocity $(\mathrm{V})$ and quality factor $(\mathrm{Q})$, which indicate the ground motion and features of near-surface sediments. Studies have reported that the V and Q vary with temperature, pore pressure, porosity, and fluid saturation (O'Connell and Budiansky 1977; Johnston et al. 1979; Winkler and Nur 1982). Temperature and fluid saturation were suggested as the most crucial factors affecting V and Q values (Shito et al. 2006). Vp, which is typically measured in laboratories and in situ seismic studies, can characterize most rock types. For example, sedimentary rocks have a low 
$\mathrm{Vp}$, whereas mafic rocks have a high $\mathrm{Vp}$. In contrast to $\mathrm{Vp}$, the $\mathrm{Vp} / \mathrm{Vs}$ ratio varies more with fluid saturation than with rock type. For example, fully fluid-saturated rocks result in a high $\mathrm{Vp} / \mathrm{Vs}$ ratio $(\mathrm{Vp} / \mathrm{Vs}>2)$, indicating high pore pressure, whereas dry or partially saturated rocks result in low $\mathrm{Vp} / \mathrm{Vs}$ ratios $(\mathrm{Vp} / \mathrm{Vs}<2$ ) (Winkler and Nur 1982). Q, which characterizes the seismic wave energy loss, is more sensitive to the rock temperature and fluid content. Toksöz et al. (1979) reported that Qs was smaller than Qp (Qs/Qp < 1) in dry and fully saturated rocks, whereas Qs was larger than Qp (Qs/Qp > 1) in partially saturated rocks. Abercrombie (1997) summarized the near surface Q of sediments in boreholes for San Andreas Fault and Cleveland Hill Fault in California. Wang et al. (2012) analyzed the near surface Q in boreholes around the Chelungpu Fault in Taiwan. The consistency of low Q values between Abercrombie (1997) and Wang et al. (2012) suggested that the dominant factor to $Q$ value was the fractures and fluids rather than rock types for the near surface sediments. Because of the differential effects of fluid saturation on P- and S-wave V and Q, using a combination of $\mathrm{V}$ and $\mathrm{Q}$ enables us to infer more precise structural features than using either of them alone does.

The unique soil conditions at different sites make the site effect considerably site-dependent. In past decades several studies on earthquake engineering have used downhole instruments for analyzing near-surface $\mathrm{V}$ and $\mathrm{Q}$ values (Liu et al. 1992; Fletcher 1995; Jongmans and Malin 1995; Abercrombie 1997). The optimal and simplest method for investigating $\mathrm{V}$ and $\mathrm{Q}$ values is comparing recordings from wellhead and borehole stations, which can eliminate the unknown source effect and straightforwardly estimate the Q and V on the connecting path (Abercrombie 2000; Wang et al. 2012). Since 2007, the Central Weather Bureau (CWB) of Taiwan has developed more than 30 borehole stations throughout Taiwan to improve the quality of recorded seismic signals and reduce the level of background noise. Downhole seismometers were deployed at depths of a few hundred meters, which were suggested to be bedrock sites. Every borehole station was equipped with a wellhead observatory. This new-generation seismic network provides early warning after rapidly assessing the seismic source parameters from high quality records and also allows characterizing the near-surface site effect.

In this study, we analyzed the data received by both downhole and wellhead instruments and estimated the Vp, Vs, Qp, and Qs values on the path between them using the spectral ratio method. The study developed Q and V models for depths of several hundred meters, which compensates for the lack of resolution in local seismic tomography and provides indicators for ground-motion studies.

\section{DATA}

The CWB developed 30 borehole stations prior to Feb- ruary 2014 (Fig. 1). Every borehole station includes three seismometers: one acceleration seismometer at the wellhead (HLX.01); one acceleration seismometer at a depth of a few hundred meters (HLX.02), the suggested bedrock site; and one broadband seismometer (HHX.02) at a distance of $0-5 \mathrm{~m}$ below the HLX.02 (Fig. 2). The broadband seismometers have a 24-bit KS-2000BH sensor with a dynamic frequency response range of $0.0083-50 \mathrm{~Hz}$. The acceleration seismometers have a PA-23 sensor with a range of dc to $100 \mathrm{~Hz}$. The data sampling rate is 100 points per second. Each station is equipped with GPS for accurately clocking the time.

From the quality data obtained between October 2011 and February 2014, we collected seismograms with an incidence angle of less than $35^{\circ}$ to ensure that the seismic waves propagated through both the downhole and wellhead seismometers. Figure 3 shows an example of the P- and S-wave travel times from the downhole to the wellhead instruments and the incidence angle of the path to the wellhead station $\mathrm{CHY}$. The ray path of every event to the CHY station was evaluated using the 1-D Vp and Vs models (Huang et al. 2014) around the site. The consistency of travel times with incidence angles of less than $35^{\circ}$ suggests little influence of incidence angles on the travel times.

A high signal-to-noise ( $\mathrm{SN}$ ) ratio was required for the data. In total 198 events with magnitudes between 1.1 and 6.6 were selected (Fig. 1). The ENAH and PNG stations were excluded from the analysis because their data did not fulfill the criteria.

Orientation correction and instrument response removal were performed before the waveform analysis. P- and $\mathrm{S}$-wave arrivals were manually picked to confirm the data quality. The short distance between HLX.02 and HHX.02 as $0-5 \mathrm{~m}$ (typically $1 \mathrm{~m}$ ) rendered the travel-time difference of signals lower than the seismogram sampling period; hence, the phase arrival consistency between the two records was considered (Fig. 3).

In addition to adopting the travel-time difference for evaluating the $\mathrm{V}$ model, signal spectra were analyzed for estimating Q. The attenuation operator $t^{*}\left(t_{p}^{*}\right.$ for P-wave and $t_{s}^{*}$ for $\mathrm{S}$-wave) was estimated using acceleration spectra after converting waveforms using the Fast Fourier transform with time windows of 0.65 and $0.35 \mathrm{sec}$ for the $\mathrm{P}$ and $\mathrm{S}$ arrival signals, respectively. Noise spectra were acquired using the same time windows before the arrival of signals to confirm the data quality and the availability of a frequency band for $t^{*}$ estimation.

Considering noise perturbation and site amplification, the available frequency bands of the analyzed data were categorized into four groups, namely $10-20,10-25,10-30$, and 10 - 40 for the P-wave spectra, and $2-15,2-20,2-25$, and $2-30 \mathrm{~Hz}$ for the S-wave spectra. The Qp and Qs values between the wellhead and downhole instruments at depths of hundreds of meters were obtained using the spectral ratio method. 


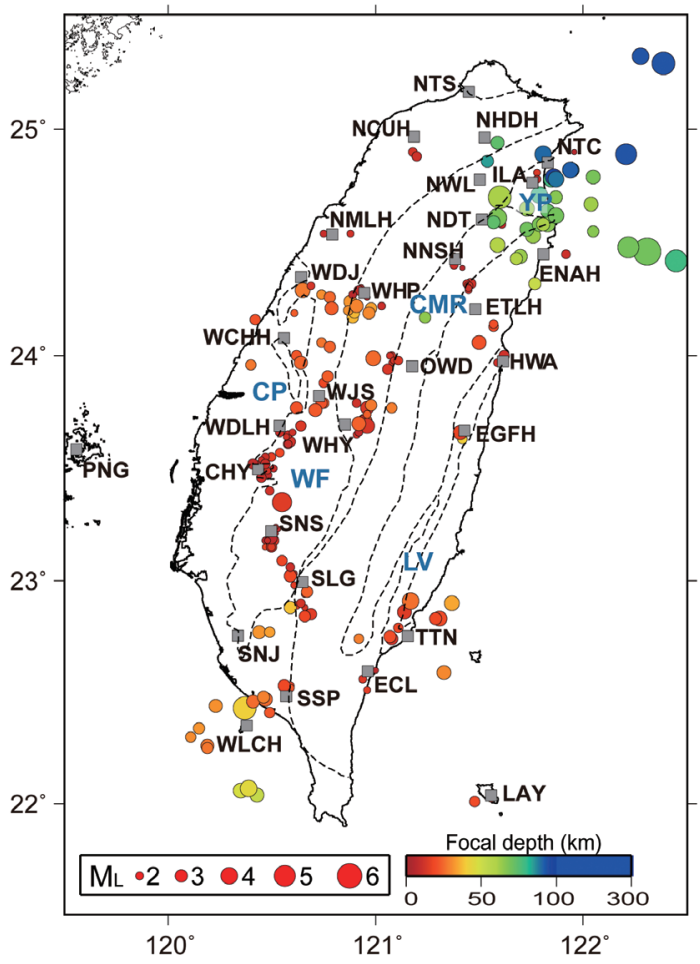

Fig. 1. Distribution of earthquakes and stations used in this study. The 30 stations of the CWB next-generation seismic network are denoted by gray squares. The 198 seismic events are shown as circles with different colors representing different focal depths. The size of the circles is proportional to the magnitude of the events. Geological provinces are denoted by $\mathrm{CP}$, the Coastal Plain; WF, the Western Foothills; CMR, the Central Mountain Range; LV, the Longitudinal Valley; and YP, Yilan Plain. (Color online only)

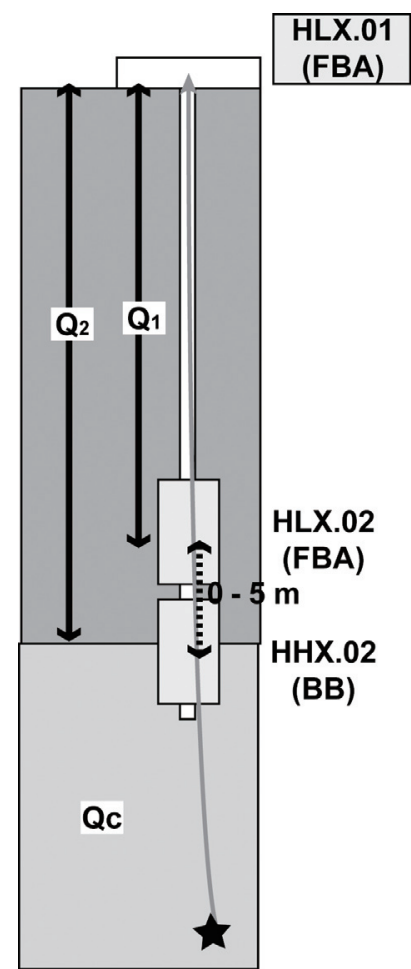

Fig. 2. Instrumental deployment at the stations of the CWB nextgeneration seismic network. HLX.01 denotes the force balance acceleration (FBA) seismometer in the wellhead. HLX.02 and HHX.02 indicate the FBA and broadband seismometers, respectively, at the borehole.

(a) $\mathrm{Vp}, \mathrm{Vs}\left(\mathrm{km} \mathrm{s}^{-1}\right)$
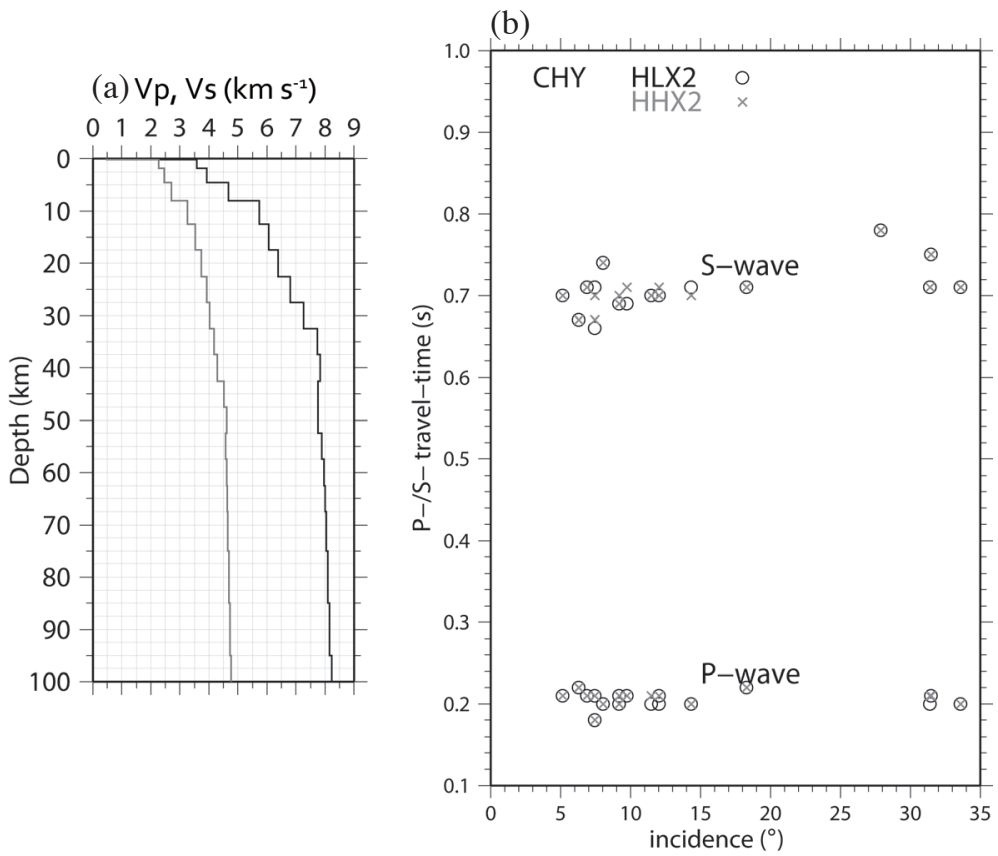

Fig. 3. (a) 1-D Vp and Vs models used in ray tracing for evaluating the incidence angles to the stations. (b) An example of the relationship between the incidence angle and travel times. The circles indicate the travel times from downhole acceleration seismometers (HLX.02) to the wellhead seismometers (HLX.01), and the crosses indicate the travel times from downhole broadband seismometers (HHX.02) to HLX.01. 


\section{METHODS}

\subsection{Spectral Ratio Method}

The near surface $\mathrm{Q}$ which is frequency independent or dependent is a controversial issue (Aster and Shearer 1991; Jin et al. 1994; Leary and Abercrombie 1994; Abercrombie 1998). Adams and Abercrombie (1998) estimated the attenuation around the Cajon Pass, southern California, and found that $\mathrm{Q}$ from surface data exhibits strong frequency dependence below $10 \mathrm{~Hz}$, but only weak frequency dependence at higher frequency. This observation was also validated by Singh et al. (2012) in the Kumaun Himalaya. Abercrombie (1997) suggested that if the frequency independent $\mathrm{Q}$ is the case, then the spectral ratios between two different recording depths will have a linear slope on a log-linear plot. This kind of analysis has been successfully used by numerous researchers such as Hauksson et al. (1987), Aster and Shearer (1991), Abercrombie (2000), and Wang et al. (2012). These studies show that the shear-wave exponential attenuation models show the linear nature of a log spectral ratio generally appearing in the frequency band of $2-30$ or $40 \mathrm{~Hz}$, and suggest weak frequency dependence of $\mathrm{Q}$ in this frequency band. The spectral ratio analysis of our data shown later demonstrates a linear signal ratio trend in $2-40 \mathrm{~Hz}$ as well (Fig. 4). Thus, the frequency independent $\mathrm{Q}$ can also be adopted here.

Derived from the formula of velocity spectrum (Wang et al. 2010; Wang and Ma 2015), the observed acceleration spectrum referring to the attenuation operator $t^{*}$ can be defined as follows:

$A(f)=(2 \pi f)^{2} \Omega_{0} \frac{f_{c}^{2}}{f^{2}+f_{c}^{2}} e^{-\pi f t^{*}}$

where $f$ and $f_{c}$ are frequency and corner frequency, (a)
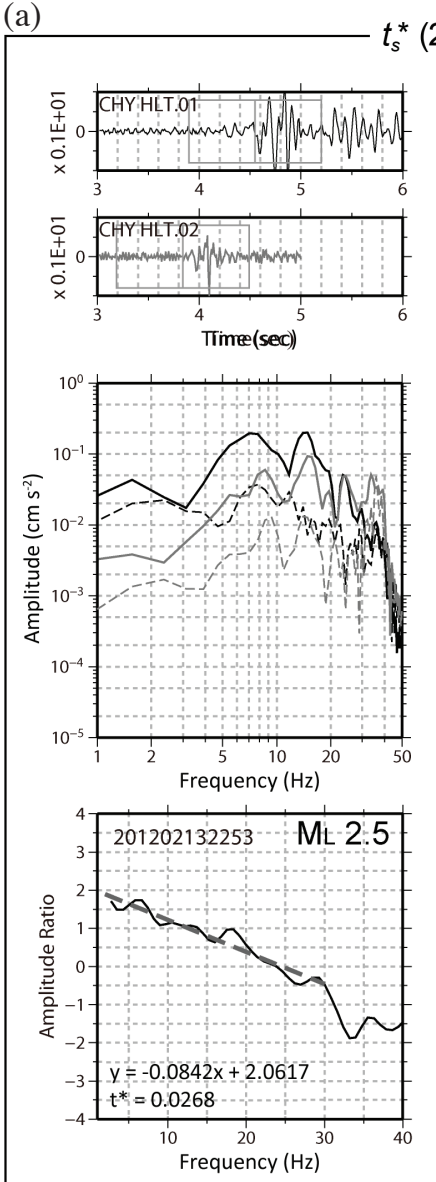

* $(2-30 \mathrm{~Hz})$
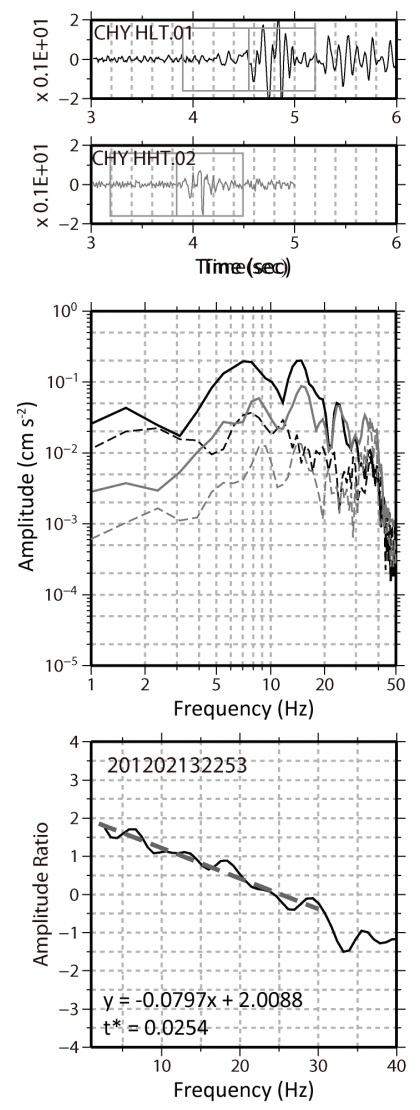

(b)
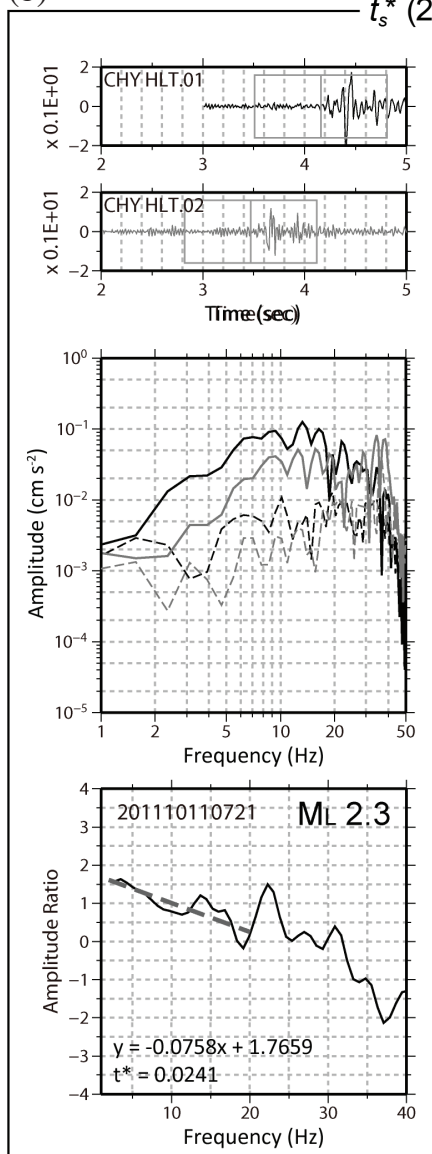

$s_{s}^{*}(2-20 \mathrm{~Hz})$
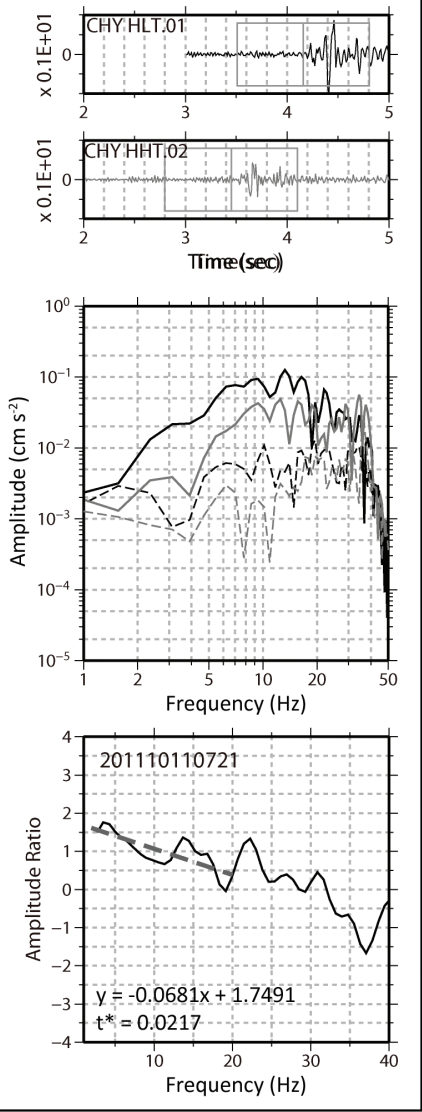

Fig. 4. Examples of spectral ratio fitting with (a) a 2 - $30 \mathrm{~Hz} \mathrm{S-wave} \mathrm{for} \mathrm{the} \mathrm{event} 201202132253$ and (b) 2 - $20 \mathrm{~Hz}$ S-wave for the event 201110110721 at the station CHY. The waveforms recorded at the T-component of HLX.01 (HLT.01), HLX.02 (HLT.02), and HHX.02 (HHT.02) with their adopted signal windows (denoted by blocks) are displayed at the top and are scaled to the same time axis and amplitude level for every specific event. (Middle) The plots of the signal spectra (black solid for HLT.01 and gray solids for HLT.02 and HHT.02) and noise spectra (black dash for HLT.01 and gray dash for HLT.02 and HHT.02) relative to the adopted windows. (Bottom) The logarithmic plots of the spectral ratio for HLT.01 over HLT.02 or HHT.02 versus frequency. The optimal fitting curve of the spectral ratio is estimated at $2-30 \mathrm{~Hz}$ for the event 201202132253 and at 2 - $20 \mathrm{~Hz}$ for the event 201110110721 . The corresponding regression equations are addressed below the plots with the resulting $t^{*}$ values. 
respectively, and $\Omega_{0}$ is the long-period plateau value. The $t^{*}$ describing the seismic-energy decay along with ray propagation is related to the $\mathrm{Q}$ of the medium and can be expressed as follows:

$t * \int_{\text {source }}^{\text {receiver }} \frac{d t}{Q}$

In this study $Q_{1}$ and $Q_{2}$ denote the $\mathrm{Q}$ values between HLX.01 and HLX.02 and between HLX.01 and HHX.02, respectively (Fig. 2). $Q c$ is the $\mathrm{Q}$ value from a seismic event to the downhole instrument. Because of the close distance and indistinct travel-time difference between HLX.02 and HHX.02, $Q_{1}$ and $Q_{2}$ were assumed to be equal. The $Q_{1}$ estimation was identical to that of $Q_{2}$. We used $Q_{1}$ as an example in the following analysis.

In the borehole observation system, $t^{*}$ observed at the wellhead instrument $\left(t_{H L X .01} *\right)$ was calculated as follows:

$t_{H L X .01} *=t_{H L X .02} *+\frac{t_{H L X .02-H L X .01}}{Q_{1}}$

where $t_{H L X .02} *$ denotes the $t^{*}$ observed at HLX.02, and $t_{H L X .02-H L X .01}$ represents the travel time from HLX.02 to HLX.01.

From Eq. (1), the logarithm of a spectral ratio between the wellhead and downhole signals for a specific event can be written as follows:

$\ln R(f)=\ln (A)-\pi f\left(t_{H L X .01} *-t_{H L X .02} *\right)$

The spectral ratio eliminates the source effect uncertainty and also provides the explicit path Q parameter under a consistent instrument response. The attenuation operator between the wellhead and downhole instruments $\left(t_{H L X .01} *-t_{H L X .02} *\right)$ was obtained from the slope of the regression analysis. $Q_{1}$ was thus evaluated according to the travel time from HLX.02 to HLX.01 using Eq. (3).

\section{2 $t^{*}$ Estimation}

The $t^{*}$ values between the wellhead and downhole instruments were estimated within the available frequency bands in the regression analysis. Figure 4 shows an example of the spectral analysis for an S-wave at the CHY station. The solid and dashed lines represent the S-wave and noise spectra, respectively. A high $\mathrm{SN}$ ratio was exhibited at frequencies less than $30 \mathrm{~Hz}$ (Fig. 4a). At frequencies higher than $30 \mathrm{~Hz}$ the noise interfered with the signal. This suggests that the available recorded frequency for the regression analysis was $2-30 \mathrm{~Hz}$. In addition to the noise disturbance, the wellhead signal distortion from amplification restricted the frequency bands available for the regression analysis. The wellhead recorded S-wave was amplified at $20-25 \mathrm{~Hz}$ and exhibited a peak in the corresponding spectral ratio (Fig. 4b). The frequency band for analyzing the regression to the record was thus constrained to $2-20 \mathrm{~Hz}$ for the $t^{*}$ analysis. Regardless of the frequency bands used for the regression analysis, the estimated $t^{*}$ values were consistent, ranging from $0.0217-0.0268$.

\section{RESULTS}

Table 1 summarizes the Vp, Vs, Qp, and Qs values estimated in this study. The $\mathrm{V}$ and $\mathrm{Q}$ values of every station were obtained by averaging the HLX.02 and HHX.02 estimations to HLX.01. The following subsections describe the Vp, Vs, Qp, and Qs values of every station and their distributions referring to structure provinces.

\subsection{Vp and Vs Models}

The Vp and Vs were assessed using the distance between the wellhead and downhole seismometers and their respective travel-time differences.

Most Vp values estimated in this study had an error of $\pm 100 \mathrm{~m} \mathrm{~s}^{-1}$. Those estimated at sites NNSH, WHY, and NDT had a higher error $\left(450-660 \mathrm{~m} \mathrm{~s}^{-1}\right)$ because of the less available data and difficulty in distinguishing signals. The $\mathrm{Vp}$ at the sites in the Coastal Plain, the Longitudinal Valley, the Yilan Plain, and the northern part of the Western Foothills was approximately $1000-2000 \mathrm{~m} \mathrm{~s}^{-1}$, which was lower than the values of $>2500 \mathrm{~m} \mathrm{~s}^{-1}$ at sites in the Central Mountain Range (Fig. 5a). The NWL and NNSH sites exhibited the highest $\mathrm{Vp}$, with 3752 and $4992 \mathrm{~m} \mathrm{~s}^{-1}$, respectively.

The error in Vs estimation was $\pm 9-371 \mathrm{~m} \mathrm{~s}^{-1}$. The largest errors, 301 and $371 \mathrm{~m} \mathrm{~s}^{-1}$, were observed at the WHY and OWD sites, respectively. The Vs at the sites in the Western Foothills was approximately $700-1100 \mathrm{~m} \mathrm{~s}^{-1}$ (Fig. 5b). In the Longitudinal Valley, the Vs was $600-900 \mathrm{~m} \mathrm{~s}^{-1}$ at the sites HWA, EGFH, and TTN. The sites in the Central Mountain Range (NWL, OWD, and NNSH) had the highest Vs, ranging from $1968-2056 \mathrm{~m} \mathrm{~s}^{-1}$.

Overall, the sites in the Coastal Plain, the Longitudinal Valley, and the Yilan Plain had lower Vp and Vs than the sites in the Central Mountain Range did. The Vp/Vs ratios at the sites in these plain areas were higher than those in the mountain area (Fig. 5c). In the Coastal Plain, the Vp/Vs ratio was approximately $3.0-4.0$. The highest $\mathrm{Vp} / \mathrm{Vs}$ ratio, 4.4, was observed at sites in the Yilan Plain. In the Central Mountain Range the $\mathrm{Vp} / \mathrm{Vs}$ ratio was less than 2.5.

\section{2 $t *$ values and Qp and Qs Models}

The available frequency bands for estimating $t^{*}$ were categorized into four groups. Figure 6 summarizes the 
different frequency bands adopted for the regression analysis along with the magnitude of events and corresponding $\mathrm{Vp}$ and Vs estimated at the stations. Most P-wave spectra were available at $10-40 \mathrm{~Hz}$ (Fig. 6a). The data available at low-frequency bands, 10 - 25 and 10 - $20 \mathrm{~Hz}$, were distributed with magnitude between 1 and 6 . However, the Vp of these data was typically less than $2000 \mathrm{~m} \mathrm{~s}^{-1}$, indicating that the records were influenced by the sites rather than the seismic sources. For the $t_{s}^{*}$ analysis (Fig. 6b), the data available for high-frequency bands, such as 25 and $30 \mathrm{~Hz}$, was concentrated on events with magnitude less than 2.5 , regardless of the Vs value. This suggests that local sites have little influence on S-wave signals from small earthquakes.

Qp and Qs were obtained at 26 stations; however, they were not obtained at the NTS and SSP stations, at which most waveforms were contaminated by noise. The averaged
Qp error estimated in this study was approximately \pm 6 . The highest Qp was $40 \pm 11$ and $38 \pm 14$ at CHY and WDLH in the Coastal Plain, respectively, and $39 \pm 4$ at NTS in the northern Taiwan. In the Western Foothills the Qp was approximately 7 - 30. The NTC and ILA sites in the Yilan Plain had a Qp of approximately 26. The HWA, EGFH, TTN, and ECL sites in the Longitudinal Valley had Qp values of 9 - 20. In the Central Mountain Range, the Qp at most sites was 6 - 16, except at NDT, where the Qp was 24. Unlike the velocity distribution, the $\mathrm{Qp}$ at sites in the Central Mountain Range was relatively lower than that in the Longitudinal Valley and the Western Foothills (Fig. 7a).

The Qs estimation error in this study was approximately \pm 5 . The Qs at sites in the Central Mountain Range and the Longitudinal Valley was significantly lower than that at sites in the Coastal Plain and the Western Foothills (Fig. 7b). In

Table 1. Vp, Vs, Qp, and Qs obtained at 28 stations. The final column shows the amount of data used for the estimation.

\begin{tabular}{|c|c|c|c|c|c|c|c|c|}
\hline station & Borehole-depth (m) & $\mathbf{V p}\left(\mathbf{m ~ s}^{-1}\right)$ & Vs $\left(\mathbf{m ~ s}^{-1}\right)$ & $\mathbf{V p} / \mathbf{V s}$ & Qp & Qs & Qs/Qp & Data amount \\
\hline CHY & 398 & $1940 \pm 95$ & $569 \pm 15$ & 3.41 & $40 \pm 11$ & $30 \pm 8$ & 0.75 & 18 \\
\hline ECL & 170 & $2712 \pm 196$ & $1232 \pm 165$ & 2.20 & $15 \pm 8$ & $10 \pm 9$ & 0.67 & 5 \\
\hline EGFH & 295 & $2188 \pm 94$ & $871 \pm 59$ & 2.51 & $19 \pm 5$ & $15 \pm 3$ & 0.77 & 2 \\
\hline ETLH & 120 & $1994 \pm 250$ & $667 \pm 88$ & 2.99 & $16 \pm 3$ & $12 \pm 4$ & 0.77 & 7 \\
\hline HWA & 294 & $2304 \pm 82$ & $612 \pm 116$ & 3.77 & $11 \pm 2$ & $12 \pm 5$ & 1.13 & 3 \\
\hline ILA & 182 & $1861 \pm 107$ & $423 \pm 20$ & 4.40 & $26 \pm 21$ & $14 \pm 3$ & 0.52 & 3 \\
\hline LAY & 197 & $1907 \pm 101$ & $907 \pm 68$ & 2.10 & $8 \pm 2$ & $8 \pm 4$ & 1.05 & 2 \\
\hline NCUH & 297 & $1927 \pm 86$ & $643 \pm 114$ & 3.00 & $24 \pm 11$ & $11 \pm 6$ & 0.44 & 6 \\
\hline NDT & 200 & $3193 \pm 453$ & $1411 \pm 114$ & 2.26 & $24 \pm 6$ & $6 \pm 1$ & 0.25 & 5 \\
\hline NHDH & 210 & $2086 \pm 226$ & $901 \pm 87$ & 2.32 & $8 \pm 8$ & $9 \pm 3$ & 1.12 & 6 \\
\hline NMLH & 297 & $1780 \pm 56$ & $706 \pm 21$ & 2.52 & $8 \pm 1$ & $25 \pm 4$ & 3.00 & 3 \\
\hline NNSH & 298 & $4992 \pm 660$ & $1979 \pm 154$ & 2.52 & $14 \pm 4$ & $6 \pm 2$ & 0.45 & 2 \\
\hline NTC & 297 & $2136 \pm 71$ & $481 \pm 26$ & 4.44 & $26 \pm 5$ & $35 \pm 6$ & 1.37 & 5 \\
\hline NTS & 297 & $1902 \pm 73$ & $514 \pm 94$ & 3.70 & $39 \pm 4$ & ---- & ---- & 2 \\
\hline NWL & 197 & $3752 \pm 309$ & $2056 \pm 159$ & 1.83 & $9 \pm 9$ & $6 \pm 2$ & 0.67 & 15 \\
\hline OWD & 290 & $3258 \pm 235$ & $1968 \pm 371$ & 1.66 & $6 \pm 1$ & $11 \pm 2$ & 1.79 & 9 \\
\hline SLG & 350 & $3217 \pm 193$ & $1494 \pm 187$ & 2.15 & $15 \pm 3$ & $20 \pm 7$ & 1.36 & 12 \\
\hline SNJ & 379 & $2050 \pm 61$ & $689 \pm 16$ & 2.97 & $9 \pm 2$ & $27 \pm 8$ & 3.00 & 3 \\
\hline SNS & 300 & $2615 \pm 128$ & $1075 \pm 53$ & 2.43 & $18 \pm 6$ & $15 \pm 6$ & 0.83 & 14 \\
\hline SSP & 295 & $1713 \pm 71$ & $481 \pm 9$ & 3.56 & $17 \pm 4$ & ---- & ---- & 5 \\
\hline TTN & 297 & $1764 \pm 237$ & $669 \pm 118$ & 2.64 & $9 \pm 6$ & $10 \pm 3$ & 1.18 & 9 \\
\hline WCHH & 297 & $1951 \pm 83$ & $558 \pm 79$ & 3.50 & $10 \pm 6$ & $24 \pm 7$ & 2.47 & 9 \\
\hline WDJ & 400 & $2042 \pm 54$ & $677 \pm 64$ & 3.02 & $7 \pm 1$ & $17 \pm 4$ & 2.38 & 5 \\
\hline WDLH & 297 & $1811 \pm 161$ & $427 \pm 29$ & 4.24 & $38 \pm 14$ & $26 \pm 10$ & 0.68 & 9 \\
\hline WHP & 122 & $1738 \pm 155$ & $901 \pm 82$ & 1.93 & $10 \pm 4$ & $22 \pm 8$ & 2.12 & 7 \\
\hline WHY & 300 & $2965 \pm 474$ & $1299 \pm 301$ & 2.28 & $23 \pm 8$ & $14 \pm 5$ & 0.59 & 11 \\
\hline WJS & 298 & $2179 \pm 95$ & $998 \pm 129$ & 2.18 & $19 \pm 9$ & $16 \pm 7$ & 0.86 & 9 \\
\hline WLCH & 167 & $1303 \pm 77$ & $660 \pm 103$ & 1.97 & $5 \pm 1$ & $11 \pm 6$ & 2.38 & 13 \\
\hline
\end{tabular}




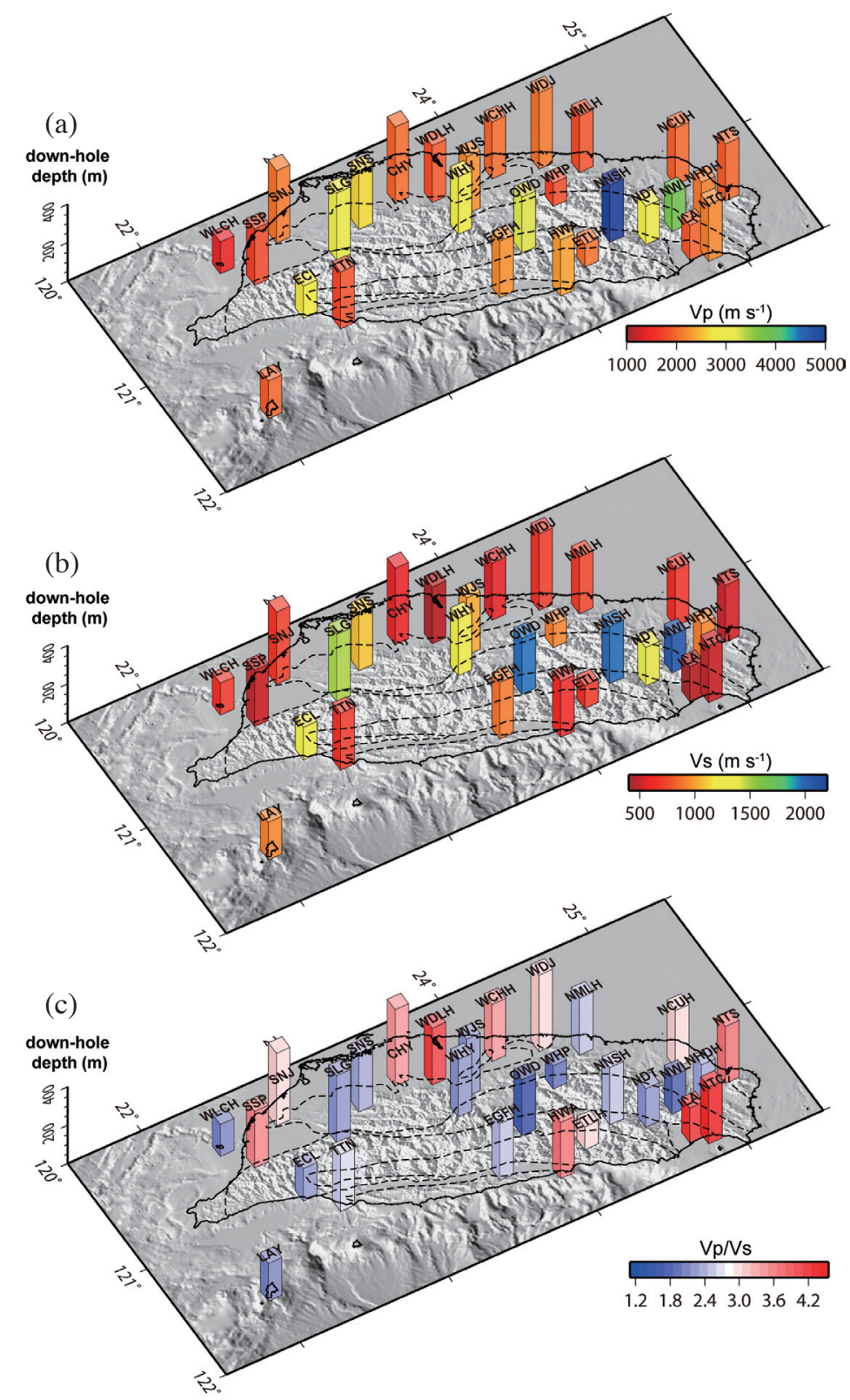

Fig. 5. Distribution of (a) Vp, (b) Vs, and (c) Vp/Vs ratio at every station. The length of the bars represents the borehole depth. (Color online only)
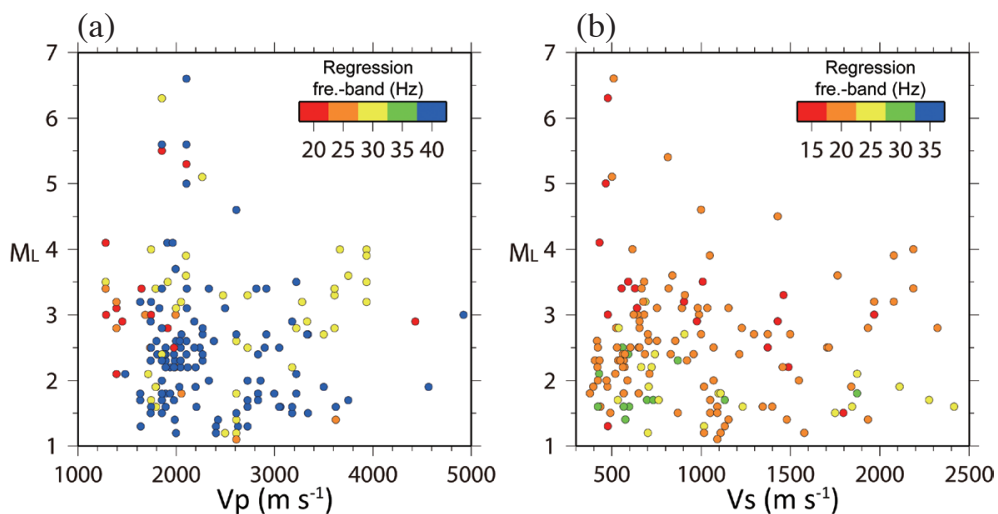

Fig. 6. Adequate frequency band of the regression analysis respective to the event magnitude and subsurface velocity at sites. (a) The regression frequency band for the P-wave spectral ratio versus Vp. (b) The regression frequency band for the S-wave spectral ratio versus Vs. (Color online only) 


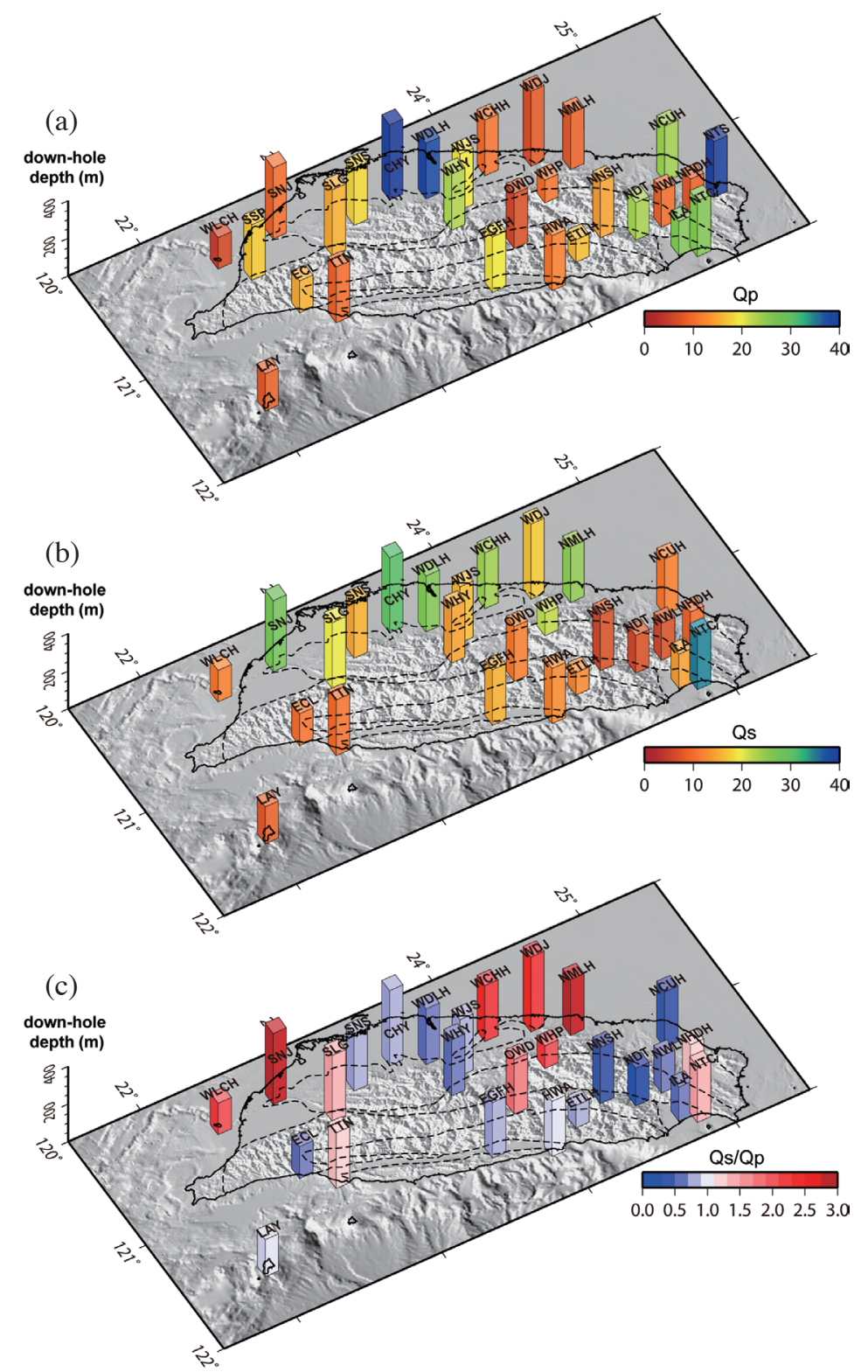

Fig. 7. Distribution of (a) Qp, (b) Qs, and (c) Qs/Qp ratio at every station. The length of the bars represents the borehole depth. (Color online only)

the Coastal Plain, the Qs at the WCHH, WDLH, CHY, and SNJ sites was approximately 24 - 30, whereas that at sites in the Central Mountain Range and the Longitudinal Valley was approximately 6 - 15, which was lower than the $15-20$ recorded at sites in the Western Foothills. The lowest Qs, approximately 6 , observed at the NWL, NDT, and NNSH sites in the northern part of the Central Mountain Range.

The range of $\mathrm{Q}$ estimated in this study was close to that obtained for soils at a depth of $0-420 \mathrm{~m}$ in California, the Qp and Qs of which were approximately 11 - 45 and 9 - 26, respectively (Hauksson et al. 1987; Malin et al. 1988; Aster and Shearer 1991; Blakeslee and Malin 1991; Jongmans and Malin 1995).

\section{DISCUSSION}

The $\mathrm{V}$ values at 28 stations (Table 1) were obtained through seismic wave analysis. Some of the stations had detailed velocity profiles, as observed from suspension PS logging measurements obtained soon after drilling at the sites. In addition to determining detailed physical properties of subsurface structure, the logging investigation examined the site condition required by borehole seismometers and yielded additional station deployment recommendations. We compared the $\mathrm{V}$ values estimated in this study with the values measured using PS logging by averaging the velocity profile (Fig. 8) (Hung et al. 2012; Wen et al. 2013). The Vp 
estimated at the NCUH, NMLH, TTN, WCHH, and WDLH stations was approximately $1750-2000 \mathrm{~m} \mathrm{~s}^{-1}$ whereas that measured using PS logging was $1500-1800 \mathrm{~m} \mathrm{~s}^{-1}$. The Vp we estimated at the CHY, NTC, and NTS stations was close to that measured by Wen et al. (2013). The largest difference in $\mathrm{Vp}$ between the seismic estimation and logging data was observed at NNSH, at which limited data was acquired in this study. The indistinct P-wave made a large discrepancy of P-arrivals among the records, and show a large deviation of $\mathrm{Vp}$ between the logging and seismic measurements; hence, this result requires further confirmation. Otherwise, the EGFH, NTS, NMLH, SNJ, and ILA stations which have less than three records acquired in this study have good data quality and distinct P-arrivals. The consistent P-arrivals among the data at each station confirmed our Vp estimation, which shows a small deviation between logging and seismic data. The Vp investigated using logging data at stations HWA, TTN, and WDLH are lower than or equal to $1500 \mathrm{~m} \mathrm{~s}^{-1}$, which approximate to the propagation velocity of sea water (Han et al. 2012; Gong et al. 2014). Hung et al. (2012) reported that the lower Vp measured using the suspension PS logging system may be due to the following reasons. First, the oversized aperture results in borehole wall sloughing, which dominates the $\mathrm{Vp}$ measurement and results in the lower $\mathrm{Vp}$ value. Second, in boreholes lined with a plastic tube for stabilizing unstable and easily eroded soils, soft backfilled soil or impractical backfilling outside the tube may result in lower velocity measurements. The traveling of seismic P- and S-wave is not restricted to the borehole wall. Thus, the measurement is not dominated by the local sloughing soils or soft/impractical backfilled soils, and the Vp estimated in this study may be more representative of the subsurface sediments.

The Vs estimated in this study was very close to that estimated using logging measurements, except that at NNSH. The Vs estimated in this study was $400-1000 \mathrm{~m} \mathrm{~s}^{-1}$, and the Vs estimated using PS logging was approximately $300-1400 \mathrm{~m} \mathrm{~s}^{-1}$. The estimations at CHY, ILA, LAY, NCUH, NMLH, NTC, NTS, TTN, WCHH, and WDLH were consistent with those based on logging measurements. The deviations at HWA and WJS were approximately 300 and $400 \mathrm{~m} \mathrm{~s}^{-1}$, respectively.

An overview of the $\mathrm{Vp}$, Vs, and $\mathrm{Vp} / \mathrm{Vs}$ ratio distribution at the analyzed sites (Fig. 5) revealed that the Coastal Plain and the Western Foothills had lower Vp, lower Vs, and a higher Vp/Vs ratio than the Central Mountain Range did. The Coastal Plain and the Western Foothills had mainly unconsolidated soils and higher pore-fluid sediments, which resulted in low $\mathrm{Vp}$ and $\mathrm{Vs}$ and a high $\mathrm{Vp} / \mathrm{Vs}$ ratio. The Central Mountain Range is comprised of metamorphic rocks; hence, it had high Vp and Vs and a low Vp/Vs ratio.

Regarding the Qp distribution (Fig. 7a), sites in the southwestern plain (SNJ, SSP, and WLCH) and the Coastal Plain (NMLH, WDJ, and WCHH) had low Qp values. The low $\mathrm{Vp}$ and $\mathrm{Vs}$ and high $\mathrm{Vp} / \mathrm{Vs}$ ratio (approximately 3 - 4.2) (Fig. 5c) indicated that fragmental soils and high water saturation resulted in high $\mathrm{P}$-wave attenuation (low Qp) in this area. Notably, all Qp values in the Central Mountain Range, except for those at NDT, were as high as 24 , and most of the Qp values in the Central Mountain Range (NWL, NNSH, and OWD) in the range of 6 - 14 were close to the Qp values in the Coastal Plain and the Western Foothills (Fig. 7b). The $\mathrm{Vp} / \mathrm{Vs}$ ratio in the Central Mountain Range was 1.66 2.52, which was significantly lower than that in the Coastal Plain and the Western Foothills (Fig. 5c). The low Vp/Vs ratio indicates that the unconsolidated soils and high porefluid content may not be a reason for the low Qp values in the Central Mountain Range. Qs, which is more sensitive to thermal temperature than Qp, also presented low values in the Central Mountain Range (Fig. 7b). The Qs in the Central Mountain Range was approximately 6 - 15, which was lower than the Qs of $24-30$ in the Coastal Plain and $15-20$ in the Western Foothills. Analyzing the Vp/Vs and Qs/Qp ratios relationship with geothermal gradients $\left(\mathrm{K} \mathrm{km}^{-1}\right)$ investigated at depths of 10 to $100-450 \mathrm{~m}$ (Wu et al. 2013) (Fig. 9) indicated that the low Qs in the Central Mountain Range corresponded closely with the low $\mathrm{Vp} / \mathrm{Vs}$ and $\mathrm{Qs} / \mathrm{Qp}$ ratios and is compatible with the high thermal gradient region. Three stations, NWL, NNSH, and OWD, which had the lowest Qs, had the highest thermal gradient. Thus, the low $\mathrm{Q}$ at sites in the Central Mountain Range is considered to be related to the high geothermal gradient beneath the surface.

The relationship between attenuation and velocity is practical for seismic engineering. Clouser and Langston (1991) evaluated the following two equations:

$Q s=\frac{4}{3}\left(\frac{V s}{V p}\right)^{2} Q p$

$Q s=\frac{V p}{V s} Q p$

for different basin thickness (1200 - $2000 \mathrm{~m}$ ) between each station. Using the average $\mathrm{Vs} / \mathrm{Vp}$ and $\mathrm{Vp} / \mathrm{Vs}$ ratios of 0.534 and 1.87 respectively, the above equations gave the lower and upper limit curves as $\mathrm{Qs}=0.38 \mathrm{Qp}$ and $\mathrm{Qs}=1.87 \mathrm{Qp}$ for Qp, Qs relationship for sedimentary basin. The measurements in this study did not show a significant relationship between Qs/Qp and Vs/Vp following Eqs. (5) and (6) (Figs. 10a and b), nevertheless, our values are mainly between the estimations of the upper and lower limit curves defined by Clouser and Langston (1991) (Fig. 10c).

\section{CONCLUSION}

By analyzing 28 borehole stations deployed throughout Taiwan, we obtained the Vp, Vs, Qp, and Qs values of 
subsurface structures at depths of approximately $300 \mathrm{~m}$. The Vp in the Coastal Plain, Western Foothills, Longitudinal Valley, and Yilan Plain was approximately $1000-2000 \mathrm{~m} \mathrm{~s}^{-1}$. The Vp in the Central Mountain Range was higher than $2500 \mathrm{~m} \mathrm{~s}^{-1}$. The Vs in the Coastal Plain and Yilan Plain was approximately $400-500 \mathrm{~m} \mathrm{~s}^{-1}$, which was the lowest among all the analyzed sites. The Vs in the Western Foothills and Longitudinal Valley was approximately $600-1000 \mathrm{~m} \mathrm{~s}^{-1}$.
The Vs in the Central Mountain Range was approximately $2000 \mathrm{~m} \mathrm{~s}^{-1}$, which was higher than that in the plain areas. The low $\mathrm{Vp}$ and $\mathrm{Vs}$ and high $\mathrm{Vp} / \mathrm{Vs}$ ratio corresponded with the unconsolidated soil properties and high pore-fluid content of shallow sediments in the Coastal Plain, Western Foothills, and Yilan Plain. The high Vp and Vs and low $\mathrm{Vp} / \mathrm{Vs}$ ratio in the Central Mountain Range was related to its metamorphic rocks.

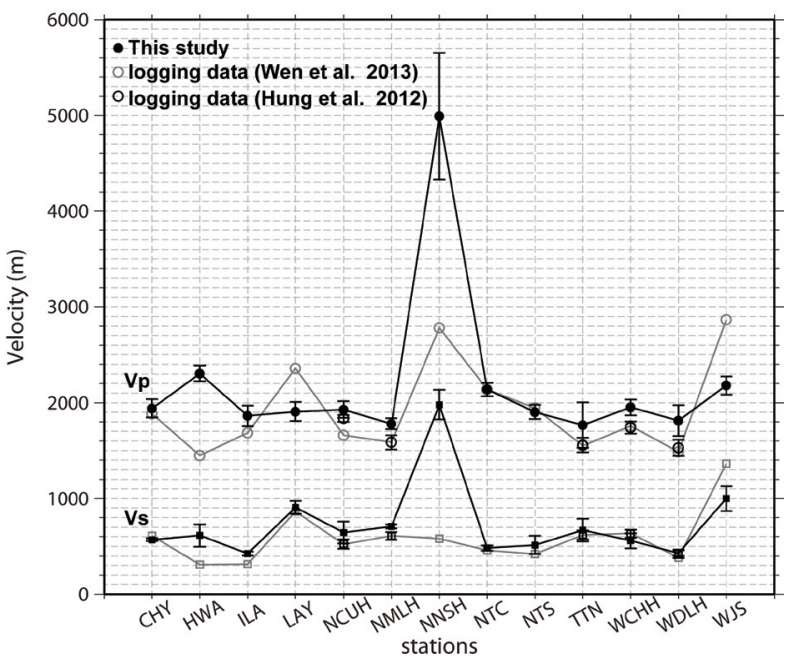

Fig. 8. Comparison of the velocity obtained in this study with the logging data at 13 stations. The Vp and Vs obtained in this study are denoted by solid dots with the respective standard deviation in caps. The gray and black circles indicate the velocity of logging data investigated by Hung et al. (2012) and Wen et al. (2013), respectively.
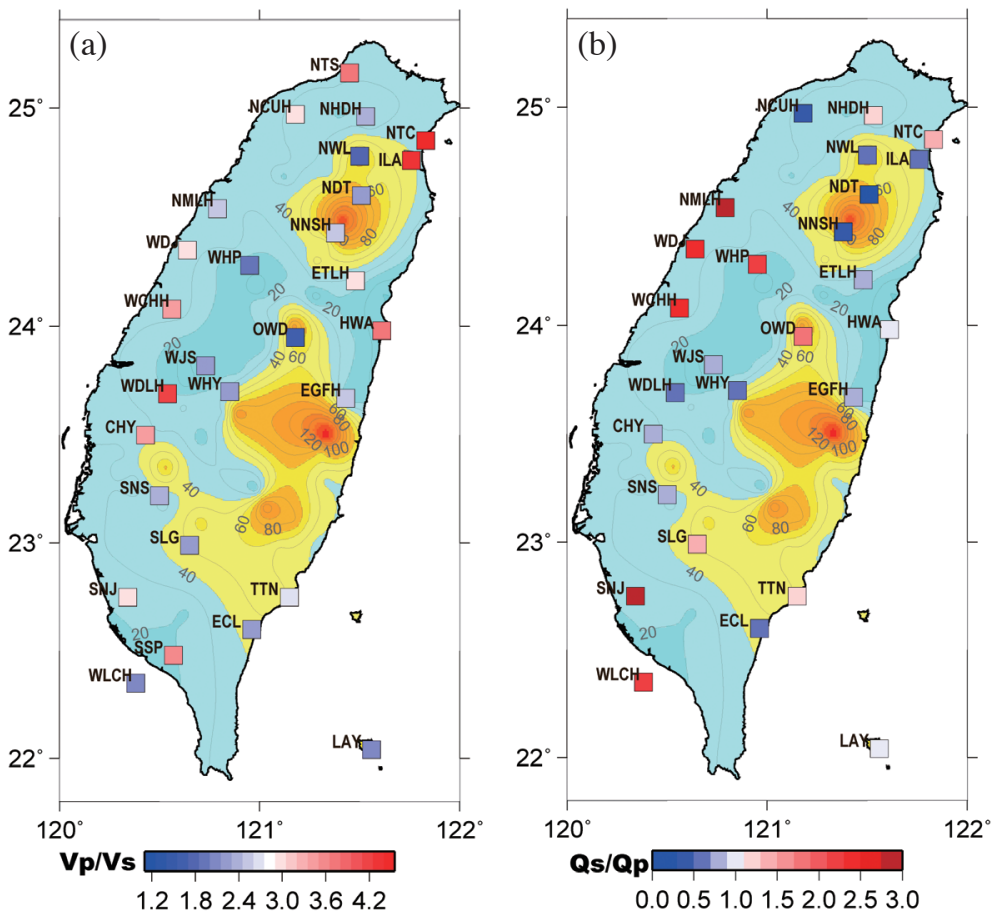

Fig. 9. Distribution of (a) $\mathrm{Vp} / \mathrm{Vs}$ and (b) Qp/Qs ratios versus the thermal gradient $\left(\mathrm{K} \mathrm{km}^{-1}\right)$ map by field investigation. A Vp/Vs ratio of 2.7 is considered the average value of the unconsolidated sediments referring to Langston (2003), and a Qs/Qp ratio of 1.0 is considered the boundary between dry and fully saturated rocks, according to an experimental study (Winkler and Nur 1982). (Color online only) 

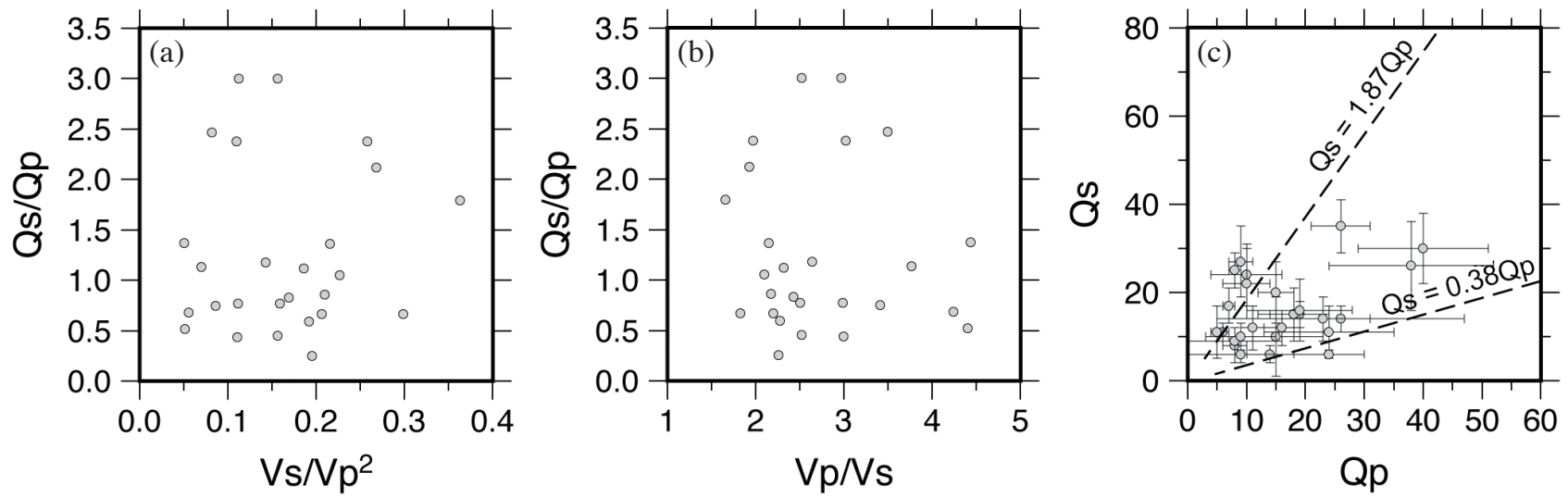

Fig. 10. Distributions of (a) (Vs/Vp) and (b) Vp/Vs versus the Qs/Qp. (c) Distribution of Qs versus Qp with deviation in thin lines. The two dashed lines denote the upper and lower limits of Qs and Qp with relationships between attenuation and velocity defined by Clouser and Langston (1991).

In contrast to the high $\mathrm{V}$ distribution, low Qp and Qs were observed in the Central Mountain Range. The highest Qp values were 40,38, and 39 at the sites CHY and WDLH in the Coastal Plain and NTS in the Western Foothills, respectively. The Qp at the sites NTC and ILA in the Yilan Plain was approximately 26. The Qp at the sites HWA, EGFH, TTN, and ECL in the Longitudinal Valley was 9 20. The estimated Qp in the Central Mountain Range was approximately $6-16$. Lower Qs was observed at the sites in the Central Mountain Range than at the sites in the other regions as well. The Qs at the sites WCHH, WDLH, CHY, and SNJ in the Coastal Plain was approximately $24-30$. The Qs at the sites in the Central Mountain Range and Longitudinal Valley was approximately 6 - 15, which was lower than the $15-20$ recorded at the sites in the Western Foothills. The lowest Qs was approximately 6 at the sites NWL, NDT, and NNSH in the northern Central Mountain Range. The low Qp, Qs, and Vp/Vs and Qs/Qp ratios corresponded closely with the high geothermal temperature of the subsurface of the Central Mountain Range and were validated by the field investigation.

Acknowledgements This work was supported by CWB grants MOTO-CWB-101-E-04, MOTO-CWB-102-E-04, and by MOTO-CWB-103-E-09. Comments and suggestions from the editor and two anonymous reviewers help us greatly improve the manuscript.

\section{REFERENCES}

Abercrombie, R. E., 1995: Earthquake source scaling relationships from -1 to $5 M_{L}$ using seismograms recorded at 2.5-km depth. J. Geophys. Res., 100, 24015-24036, doi: 10.1029/95JB02397. [Link]

Abercrombie, R. E., 1997: Near-surface attenuation and site effects from comparison of surface and deep borehole recordings. Bull. Seismol. Soc. Am., 87, 731-744.
Abercrombie, R. E., 1998: A summary of attenuation measurements from borehole recordings of earthquakes: The $10 \mathrm{~Hz}$ transition problem. Pure Appl. Geophys., 153, 475-487, doi: 10.1007/s000240050204. [Link]

Abercrombie, R. E., 2000: Crustal attenuation and site effects at Parkfield, California. J. Geophys. Res., 105, 6277-6286, doi: 10.1029/1999JB900425. [Link]

Abercrombie, R. E. and P. Leary, 1993: Source parameters of small earthquakes recorded at $2.5 \mathrm{~km}$ depth, Cajon Pass, southern California: Implications for earthquake scaling. Geophys. Res. Lett., 20, 1511-1514, doi: 10.1029/93GL00367. [Link]

Adams, D. A. and R. E. Abercrombie, 1998: Seismic attenuation above $10 \mathrm{~Hz}$ in southern California from coda waves recorded in the Cajon Pass borehole. J. Geophys. Res., 103, 24257-24270, doi: 10.1029/98JB01757. [Link]

Aster, R. C. and P. M. Shearer, 1991: High-frequency borehole seismograms recorded in the San Jacinto Fault zone, Southern California Part 2. Attenuation and site effects. Bull. Seismol. Soc. Am., 81, 1081-1100.

Blakeslee, S. and P. Malin, 1991: High-frequency site effects at two Parkfield downhole and surface stations. Bull. Seismol. Soc. Am., 81, 332-345.

Clouser, R. H. and C. A. Langston, 1991: $Q p-Q s$ relations in a sedimentary basin using converted phases. Bull. Seismol. Soc. Am., 81, 733-750.

Fletcher, J. B., 1995: Source parameters and crustal Q for four earthquakes in South Carolina. Seismol.Res. Lett., 66, 44-61, doi: 10.1785/gssrl.66.4.44. [Link]

Gong, J., X. Zhang, C. Zou, Q. Chen, L. Wang, C. Yuan, G. $\mathrm{Hu}$, and Y. Jiang, 2014: Revision of P-wave velocity and thickness of hydrate layer in Shenhu Area, South China Sea. J. Ocean Univ. China, 13, 742-746, doi: 10.1007/s11802-014-2252-y. [Link]

Han, F. X., J. G. Sun, and K. Wang, 2012: The influence of sea water velocity variation on seismic traveltimes, ray paths, and amplitude. Appl. Geophys., 9, 319-325, doi: 
10.1007/s11770-012-0344-2. [Link]

Hauksson, E., T. Teng, and T. L. Henyey, 1987: Results from a $1500 \mathrm{~m}$ deep, three-level downhole seismometer array: Site response, low $Q$ values, and $f_{\max }$. Bull. Seismol. Soc. Am., 77, 1883-1904.

Huang, H. H., Y. M. Wu, X. Song, C. H. Chang, S. J. Lee, T. M. Chang, and H. H. Hsieh, 2014: Joint Vp and Vs tomography of Taiwan: Implications for subductioncollision orogeny. Earth Planet. Sci. Lett., 392, 177191, doi: 10.1016/j.eps1.2014.02.026. [Link]

Hung, J. H., P. C Yan, J. S. Cai, J. H. Jiang, and S. S. Wang, 2012: The evaluation of mechanical properties of borehole sites by integrating core samples, logging, and rock physical mechanical data. CWB Annual Reports, Vol. 61, MOTC-CWB-101-E-18. (in Chinese)

Jin, A., K. Mayeda, D. Adams, and K. Aki, 1994: Separation of intrinsic and scattering attenuation in southern California using TERRAscope data. J. Geophys. Res., 99, 17835-17848, doi: 10.1029/94JB01468. [Link]

Johnston, D. H., M. N. Toksöz, and A. Timur, 1979: Attenuation of seismic waves in dry and saturated rocks: II. Mechanisms. Geophysics, 44, 691-711, doi: 10.1190/1.1440970. [Link]

Jongmans, D. and P. E. Malin, 1995: Microearthquake $S$ wave observations from 0 to $1 \mathrm{~km}$ in the Varian well at Parkfield, California. Bull. Seismol. Soc. Am., 85, 1805-1820.

Langston, C. A., 2003: Local earthquake wave propagation through Mississippi embayment sediments, Part I: Body wave phases and local site responses. Bull. Seismol.Soc. Am., 93, 2664-2684, doi: 10.1785/0120030046. [Link]

Leary, P. and R. Abercrombie, 1994: Frequency dependent crustal scattering and absorption at $5-160 \mathrm{~Hz}$ from coda decay observed at $2.5 \mathrm{~km}$ depth. Geophys. Res. Lett., 21, 971-974, doi: 10.1029/94GL00977. [Link]

Liu, H. P., R. E. Warrick, R. E. Westerlund, E. D. Sembera, and L. Wennerberg, 1992: Observation of local site effects at a downhole-and-surface station in the Marina District of San Francisco. Bull. Seismol. Soc. Am., 82, 1563-1591.

Malin, P. E., J. A. Waller, R. D. Borcherdt, E. Cranswick, E. G. Jensen, and J. van Schaack, 1988: Vertical seismic profiling of Oroville microearthquakes: Velocity spectra and particle motion as a function of depth. Bull. Seismol. Soc. Am., 78, 401-420.

O'Connell, R. J. and B. Budiansky, 1977: Viscoelastic properties of fluid-saturated cracked solids. J. Geophys.
Res., 82, 5719-5735, doi: 10.1029/JB082i036p05719. [Link]

Shito, A., S. I. Karato, K. N. Matsukage, and Y. Nishihara, 2006: Towards mapping the three-dimensional distribution of water in the upper mantle from velocity and attenuation tomography. In: Jacobsen, S. D. and S. Van Der Lee, Earth's Deep Water Cycle, American Geophysical Union, Washington, D. C., 225-236, doi: 10.1029/168GM17. [Link]

Singh, C., A. Singh, V. K. S. Bharathi, A. R. Bansal, and R. K. Chadha, 2012: Frequency-dependent body wave attenuation characteristics in the Kumaun Himalaya. Tectonophysics, 524-525, 37-42, doi: 10.1016/j.tecto.2011.12.013. [Link]

Toksöz, M. N., D. H. Johnston, and A. Timur, 1979: Attenuation of seismic waves in dry and saturated rocks: I. Laboratory measurements. Geophysics, 44, 681-690, doi: 10.1190/1.1440969. [Link]

Wang, Y. J. and K. F. Ma, 2015: Investigation of the temporal change in attenuation within the ruptured fault zone of the 1999 Mw7.3 Chi-Chi, Taiwan earthquake. Pure Appl. Geophys., 172, 1291-1304, doi: 10.1007/s00024014-0854-3. [Link]

Wang, Y. J., K. F. Ma, F. Mouthereau, and D. Eberhart-Phillips, 2010: Three-dimensional $Q p$ - and $Q s$-tomography beneath Taiwan orogenic belt: Implications for tectonic and thermal structure. Geophys. J. Int., 180, 891-910, doi: 10.1111/j.1365-246X.2009.04459.x. [Link]

Wang, Y. J., Y. Y. Lin, M. C. Lee, and K. F. Ma, 2012: Fault zone $Q$ values derived from Taiwan Chelungpu Fault borehole seismometers (TCDPBHS). Tectonophysics, 578, 76-86, doi: 10.1016/j.tecto.2011.12.027. [Link]

Wen, K. L., C. H. Kuo, J. D. Chen, J. Y. Huang, K. W. Guo, G. C. Chen, and K. J. Syu, 2013: The analysis of siteeffect for CWB borehole and surface stations. CWB Annual Reports, Vol. 63, MOTC-CWB-102-E-02. (in Chinese)

Winkler, K. W. and A. Nur, 1982: Seismic attenuation: Effects of pore fluids and frictional-sliding. Geophysics, 47, 1-15, doi: 10.1190/1.1441276. [Link]

Wu, S. K., W. C. Chi, S. M. Hsu, C. C. Ke, and Y. Wang, 2013: Shallow crustal thermal structures of central Taiwan foothills region. Terr. Atmos. Ocean. Sci., 24, 695-707, doi: 10.3319/TAO.2013.03.13.01(T). [Link]

Zeng, Y. and J. G. Anderson, 1996: A composite source model of the 1994 Northridge earthquake using genetic algorithms. Bull. Seismol. Soc. Am., 86, S71-S83. 